\title{
DYDAKTYKA PRZEKŁADU TEKSTÓW SPECJALISTYCZNYCH W KONTEKŚCIE ROZWOJU KOMPETENCJI TŁUMACZENIOWE
}

\footnotetext{
Zarys treści: Przed tłumaczami stoją obecnie wielkie wyzwania, sprostanie którym wymaga ciągłego poszerzania wiedzy, zapoznawania się z nowymi technologiami i technikami tłumaczenia czy też umiejętności poszukiwania potrzebnych informacji. W niniejszym artykule odniesiemy się zatem do przekładu tekstów specjalistycznych, w szczególności zaś do przekładu tekstów prawnych, z punktu widzenia dydaktyki przekładu, jak również zajmiemy się kwestią niezbędną dla wygenerowania dobrego przekładu, a mianowicie możliwością rozwoju kompetencji tłumaczeniowej z perspektywy dydaktycznej.
}

Drzekład tekstów specjalistycznych charakteryzuje się znaczną dynamiką rozwoju, co związane jest z udziałem Polski nie tylko w Unii Europejskiej, ale też rosnącym zaangażowaniem wielu polskich firm w procesy gospodarcze zachodzące w różnych krajach na wszystkich niemal kontynentach. Istotne jest, aby tłumaczenie tego rodzaju tekstów dokonywane było w sposób adekwatny, precyzyjny i terminologicznie spójny z uwagi na ich olbrzymie zróżnicowanie tematyczne. Język tych dokumentów również podlega ciągłym zmianom - z racji funkcjonowania angielskiego jako lingua franca większość przekładów dokonywanych jest bądź z tego języka, bądź na ten właśnie język. Jego doskonała znajomość jest warunkiem sine qua non dla osób, które w tłumaczeniu profesjonalnym (zawodowym) upatrują dla siebie szansy na dalszy rozwój i karierę zawodową.

Wśród typów języków specjalistycznych można wyróżnić język prawny i prawniczy - język prawny jest językiem ustawodawcy, a jego podstawowym źródłem są przepisy prawne, natomiast językiem prawniczym po- 
sługują się prawnicy (szczegółowy dalszy podział zob. Jopek-Bosiacka 2006). W niniejszym artykule, w celu uniknięcia niejednoznaczności, w kontekście tłumaczenia posługiwać się będziemy terminem „teksty prawne”. Teksty prawne to również cała olbrzymia dziedzina tekstów normatywnych UE, których przekład jest wymagany prawem $\mathrm{w}$ ramach członkowstwa Polski w UE. Język tekstów prawnych to, jak już wspomniano, przede wszystkim język specjalistyczny, a więc charakteryzujący się relewantnymi cechami; Sarcevic (2000) postrzega go nawet jako subjęzyk z przynależnymi mu specyficznymi cechami syntaktycznymi, pragmatycznymi czy semantycznymi. Co więcej, język ten ma specjalistyczne i specyficzne słownictwo precyzyjnie opisujące rzeczywistość, w której funkcjonują akty prawne. Terminy pojawiające się $\mathrm{w}$ tekstach prawnych i dotyczące danego systemu prawnego często nie mają relewantnych odpowiedników w innych systemach $\mathrm{z}$ racji braku w danym systemie czynności, rzeczy czy obiektu (Sarcevic 1997). Sarcevic (1988) określa je mianem terminów wiążących się z systemem prawa (system-bound terms); z powodu ich osadzenia w konkretnym systemie prawnym są one bardzo często nieprzetłumaczalne lub ich tłumaczenie dokonywane jest na zasadzie opisu pojęcia (np. equity). Generalnie można zaobserwować pewną koncepcyjną niespójność w obrębie terminologii - Sarcevic (2000) upatruje przyczyn tej sytuacji w historycznej ewolucji systemów prawnych, z których każdy wykształcił własny repertuar pojęciowy odnoszący się do realiów społeczno-ekonomicznych, historii czy kultury danego państwa.

Jest kilka cech charakterystycznych dla tekstów prawnych, które pokrótce opiszemy poniżej. W przypadku polskiego dyskursu prawnego można je podzielić na trzy grupy: językowe, komunikacyjne i stylistyczne. Cechami językowymi są dyrektywność i kategoryczność (Wojtak 2001, Jadacka 2002), a także standaryzacja (Wojtak 2001) oraz terminologiczność (Hałas 1995). Cechy komunikacyjne to precyzyjność, czyli jak najbardziej konsekwentne stosowanie terminów (Wojtak 2001), adekwatność do opisywanego przedmiotu (Jadacka 2002) oraz zrozumiałość (Wojtak 2001). Natomiast cechami stylistycznymi są bezosobowość lub też skrótowość, która ma na celu osiągnięcie maksymalnej precyzji wypowiedzi (Wojtak 2001). Inną istotną cechą języka polskich tekstów prawnych są liczne zapożyczenia z łaciny, niemieckiego, francuskiego i angielskiego (Jopek-Bosiacka 2006).

Angielski dyskurs prawny również charakteryzuje się specyficznymi cechami (Tiersma 1999), spośród których można wymienić:

1. precyzję,

2. niedookreśloność (terminy nieostre), 
3. konserwatyzm (np. stosowanie łacińskich zwrotów czy archaicznych konstrukcji),

4. specjalizację (stosowanie terminologii),

5. złożoność na poziomie wyrazu (nominalizacje), na poziomie zdania (stosowanie strony biernej) oraz na poziomie tekstu (specyficzne stosowanie interpunkcji).

Tłumaczenie tekstów prawnych jest więc zadaniem trudnym, złożonym i wymagającym od tłumacza świadomości różnic istniejących nie tylko pomiędzy językami czy dyskursami, ale także pomiędzy systemami. Przekład tekstu prawnego wymaga zatem od tłumacza wiedzy i umiejętności pozwalających na dobry i profesjonalny - innymi słowy kompetentny przekład. Kwestia kompetencji tłumaczeniowej stanowić będzie więc następny punkt naszych rozważań. W niniejszym artykule spojrzymy na kompetencję tłumaczeniową $\mathrm{w}$ sensie dydaktyzacji przekładu na kierunkach filologicznych realizowanego w ramach komponentu praktycznej nauki języka (PNJ).

\section{Kompetencja tłumaczeniowa}

Kompetencja tłumaczeniowa zajęła istotne miejsce na polu badań nad przekładem stosunkowo późno, czyli w latach 90. ubiegłego wieku. Powracającym stale problemem $\mathrm{w}$ rozważaniach dotyczących kompetencji jest niezliczona liczba definicji tego zjawiska, w których trudno znaleźć wspólny mianownik; zakres definicji $\mathrm{w}$ dużej mierze odzwierciedla paradygmaty badawcze - od podejść językoznawczych aż do psychologii kognitywnej czy neurolingwistyki. Truizmem jest stwierdzenie, że problemem w określaniu kompetencji jest nieograniczona liczba kryteriów, które należałoby wziąć pod uwagę $\mathrm{w}$ definiowaniu kompetencji, a także trudność $\mathrm{z}$ ich hierarchizacją. Modele tworzone przez badaczy w pewnym sensie ułatwiają (czasami w sposób pozorny) poszukiwanie domen, w których kompetencja tłumaczeniowa jest realizowana. $\mathrm{W}$ badaniach empirycznych związanych z procesem przekładu (np. Krings 1986, Gerloff 1986 oraz 1988, Séguinot 1989, Tirkkonen-Condit 1990 oraz 1992, Jääskeläinen 1996, Alves 1995, Danks 1997, Schäffner oraz Adab 2000) często nie precyzowano spektrum kompetencji tłumaczeniowej.

Jednym $\mathrm{z}$ wymiernych rezultatów badań empirycznych jest model opracowany przez grupę PACTE (Beeby 2000), z którego wynika, że kompetencja tłumaczeniowa stanowi holistyczny system wiedzy oparty na czterech założeniach: 
a) wiedza ta jest domeną ekspertów i osoby bilingwalne jej nie przejawiają,

b) jest to głównie wiedza proceduralna (magazynowana w postaci reguł, procedur i strategii, a nie wiedza deklaratywna magazynowana w postaci wzorów i reguł; por. Anderson 1983, Sternberg 1999),

c) jest wynikiem wzajemnego oddziaływania powiązanych (sub)kompetencji,

d) elementem integrującym powyższe oddziaływanie jest strategia.

Model kompetencji tłumaczeniowej PACTE obejmuje 5 (sub)kompetencji oraz komponentów psychofizjologicznych (szersze omówienie modelu PACTE oraz innych modeli kompetencji znajduje się w Kościałkowska-Okońska 2012). Model PACTE posłużył również za podstawę modelu kompetencji tłumaczeniowej zaproponowanego przez Alvesa i Goncalves (2003; również Alves 2005), w którym jednak położono znacznie większy nacisk na (indywidualną) kompetencję tłumacza i ilustrację różnych etapów nabywania kompetencji tłumaczeniowej. Model PACTE definiuje kompetencję tłumaczeniową jako realizację wiedzy proceduralnej, a nie deklaratywnej. Alves natomiast (również zob. Alves 2000) twierdzi, że wiedza deklaratywna tłumacza może przyczynić się do podniesienia jakości tworzonego przez tłumacza tekstu, ponieważ stanowi istotny element kompetencji tłumaczeniowej; co więcej, może spełniać ważną rolę w dalszym rozwoju tejże, gdyż pomaga zwiększyć stopień świadomego monitorowania przez tłumacza procesów tłumaczeniowych i tym samym wpływać na ostateczną jakość tworzonego tekstu.

Kompetencja tłumaczeniowa służy zatem tłumaczowi do identyfikowania problemów (mogących wystąpić w trakcie procesu przekładu); dzięki kompetencji tłumacz zdaje sobie sprawę z obszarów, w odniesieniu do których ma deficyt poznawczy, co z kolei może (i powinno) stanowić dla niego motywację do pogłębiania i gromadzenia wiedzy, w naturalny sposób przyczyniając się do gromadzenia niezbędnego w pracy doświadczenia. Podobny ton rozważań można znaleźć u Kiraly’ego (2000) w dokonanym przez niego rozróżnieniu na kompetencję tłumaczeniową (translatorską, translation competence) i kompetencję tłumacza (translator competence). Kompetencja tłumaczeniowa daje tłumaczowi możliwość i umiejętność tworzenia tekstów w języku docelowym; kompetencja tłumacza to umiejętność zastosowania wiedzy i zdobytych informacji w celu tworzenia dobrych jakościowo (w percepcji użytkowników) tekstów w języku docelowym. Widać wyraźnie w założeniach Kiraly’ego ewolucyjność kompetencji: od ogólnej tłumaczeniowej do indywidualnej tłumacza, opartej na zgromadzonej (i powiększanej wiedzy), umiejętności szukania oraz wykorzystywania zdobytych informacji, a tak- 
że coraz większej specjalizacji (nabierającej charakteru wiedzy eksperckiej) w zetknięciu z nowymi zadaniami tłumaczeniowymi.

Rozwój i nabywanie kompetencji tłumaczeniowej były od wielu już lat przedmiotem debat i rozważań, kompetencji rozumianej nie jako naturalna umiejętność tłumaczenia u osób znających język źródłowy i docelowy (tak jak ujmował to Lörscher 1991) czy wynik działania „native translator” w ujęciu Toury’ego (1995), ale - najprościej rzecz ujmując - świadomości, że przekład to coś więcej niż (nawet doskonała) znajomość dwóch języków. Tworzenie modeli kompetencji tłumaczeniowej pozwalających na generowanie wniosków dotyczących jej rozwoju w dużej mierze opiera się na takich podstawach jak wyniki badań empirycznych przeprowadzanych na studentach kierunków filologicznych, studentach specjalizujących się w tłumaczeniu czy wreszcie profesjonalnych tłumaczach ( $\mathrm{z}$ dużą przewagą liczebną dwóch pierwszych grup, co czasami może rodzić pewien niedosyt, zwłaszcza w odniesieniu do wniosków płynących z tych badań). Do wyżej wymienionych filarów zaliczamy również rozważania teoretyczne prowadzące do kreowania równie teoretycznych modeli kompetencji, często trudnych do zweryfikowania w praktyce $\mathrm{z}$ racji faktu, iż proces tłumaczeniowy w dużej mierze opiera się na operacjach poznawczych, do których badacze mają ograniczony dostęp (choć tutaj należy zaznaczyć, że najnowsze zdobycze techniki, takie jak np. pozytonowa tomografia emisyjna, pozwalają na wgląd w aktywność mózgu). Niezwykle istotne są również badania dotyczące rozwoju kompetencji eksperckiej w psychologii kognitywnej (np. Ericsson i Smith 1991). Ograniczenia niniejszego artykułu nie pozwalają na szersze przedstawienie wyników różnych badań empirycznych nad procesem przekładu z udziałem uczestników charakteryzujących się różnym poziomem kompetencji tłumaczeniowej (pisze o tym Jääskeläinen 2002).

Dla Hurtado Albir (2005) wspomniany już wyżej model PACTE w kontekście nabywania kompetencji tłumaczeniowej jest procesem restrukturyzowania i rozwoju wiedzy u początkującego niedoświadczonego tłumacza (nowicjusza), ewoluującej od początkowej kompetencji - obejmującej cechującą wszystkie osoby bilingwalne umiejętność tłumaczenia - poprzez wszystkie etapy rozwoju kompetencji, aż do etapu eksperta (por. Dreyfus i Dreyfus 1986 czy Chesterman 1997), czyli do etapu, w którym mamy do czynienia $\mathrm{z}$ wyspecjalizowaną i specjalistyczną wiedzą. Można w wymienionych powyżej etapach restrukturyzowania i rozwoju dostrzec pewną zbieżność z koneksjonistycznym podejściem do kształtowania kompetencji i nabywania wiedzy, gdzie proces gromadzenia wiedzy przebiega stopniowo i staje się coraz bardziej złożony. W tym miejscu warto wspomnieć o modelu zapro- 
ponowanym przez Gonçalves (2003), który łączy różne aspekty operowania kompetencji w wymiarze poznawczym w zależności od stopnia zaawansowania wiedzy (eksperckiej) i doświadczenia danego tłumacza. W modelu tym kompetencja jest swoistym konstruktem poznawczym, superkompetencją, rozwijającą się stopniowo na podstawie działań tłumacza. Superkompetencja będzie w sposób oczywisty manifestowana raczej przez ekspertów, którzy w większym stopniu i bardziej świadomie wykorzystują procesy poznawcze, podejmując decyzje w sposób świadomy i lepiej zarządzając zasobami poznawczym w trakcie procesu tłumaczeniowego. $Z$ drugiej strony początkujący niedoświadczeni tłumacze (co widać w badaniach np. Jääskeläinen 1989, Tirkkonen-Condit 1990 czy Alves 1995) w mniejszym stopniu podejmują decyzje świadomie i gorzej zarządzają zasobami kognitywnymi w trakcie procesu tłumaczeniowego.

Badania empiryczne dotyczące procesu tłumaczeniowego oraz wynikających $\mathrm{z}$ tego wniosków dla prób zdefiniowania kompetencji tłumaczeniowej opierają się na zastosowaniu różnych metod, za pomocą których można uzyskać rozmaite informacje dotyczące procesu przekładu. Ponieważ w niniejszym artykule nie ma miejsca na szczegółowe omówienie metodologii badań, skupimy się na pewnych tendencjach natury ogólnej, które udało się wyodrębnić.

Już we wczesnych badaniach (por. Gerloff 1986, Krings 1988, Jääskeläinen 1999) udowodniono, że jednostki tłumaczeniowe, na których skupiają się tłumacze, stają się coraz obszerniejsze wraz ze wzrostem doświadczenia, które również pozwala na rozwiązywanie bardziej złożonych problemów na poziomie tekstu, a nie na poziomie słowa. Zatem doświadczeni tłumacze tworzą makrostrategie w rozumieniu Höniga (1995) czy też strategie globalne (por. Jääskeläinen 1993). Przetwarzają informacje w sposób nielinearny i przywiązują większą wagę do wiedzy z kontekstu (np. Krings 1988, Tirkkonen-Condit 1992, por. Kościałkowska-Okońska 2012). Większa kompetencja tłumaczeniowa pozwala również tłumaczom na manifestowanie większej świadomości dotyczącej istniejących problemów tłumaczeniowych, generowanie i krytyczną analizę powstających ekwiwalentów. Ponadto doświadczeni tłumacze korzystają ze źródeł odmiennie niż tłumacze początkujący, a mianowicie stosują je głównie w celu rozwiązywania problemów związanych $\mathrm{z}$ generowaniem tekstu, w przeciwieństwie do nowicjuszy, dla których źródła są sposobem na rozwiązanie problemów z rozumieniem tekstu. W badaniach Jääskeläinen i Tirkkonen-Condit (1991) dotyczących automatyzacji procesu tłumaczeniowego wyraźnie widać, jak rosnąca kompetencja tłumaczeniowa wpływa na przebieg procesu podejmowania decyzji: przy większym 
stopniu automatyzacji można skupić większą część zdolności przetwarzania informacji na rozwiązywaniu bardziej złożonych problemów (pisze o tym również Englund Dimitrova 2005).

Kompetencja tłumaczeniowa i jej definicja nadal stanowią pewne konceptualne wyzwanie. Ponieważ nie ma jednej i obowiązującej definicji - a raczej mamy do czynienia z wieloma modelami i komponentami - należy się zastanowić, czym jest kompetencja tłumaczeniowa w kontekście naszych rozważań dotyczących kształcenia. Trudno odnosić się wyłącznie krytycznie do „multiskładnikowych” modeli i definicji kompetencji z racji faktu, że wyjaśnienie natury zjawiska $\mathrm{w}$ sposób szczegółowy może pomóc nam uzyskać szerszy obraz związanych z nim aspektów czy zwrócić uwagę na zjawiska dotychczas pomijane. Należy jednakże przede wszystkim skupić się na kompetencji tłumaczeniowej z perspektywy jednostki, a nie z perspektywy nieco jednak odhumanizowanych czy wręcz „technicznych” aspektów kompetencji tłumaczeniowej. Jednostka - tłumacz - powinna mieć różne rodzaje kompetencji (językową, IT, kulturową etc.), aby móc je wykorzystywać do tłumaczenia - kompetencja jako byt abstrakcyjny nie może przecież być odpowiedzialna za przekład. Skupienie się na kształtowaniu jednostki, a nie na kształtowaniu abstrakcyjnych bytów kompetencyjnych pozwala na zmianę perspektywy dydaktycznej. Tłumacz powinien zatem nabywać i rozwijać nie tylko kompetencję tłumaczeniową (rozumianą jako konglomerat różnych umiejętności), ale powinien także kształtować w sobie kompetencję tłumacza. O tej szczególnej kompetencji pisał już Kiraly (2000), ale oprócz wspomnianych przez niego takich umiejętności jak określanie norm w społecznościach, do których chcemy uzyskać dostęp, i stosowanie narzędzi oraz informacji w celu stworzenia komunikatywnie efektywnych tekstów akceptowanych jako teksty dobre jakościowo dla danych odbiorców, chcemy dołączyć inne umiejętności czy rodzaje kompetencji, których potrzebuje tłumacz. A zatem nasza zakładana specjalistyczna kompetencja, którą powinien charakteryzować się tłumacz, obejmuje kompetencję poznawczą (na którą składają się wiedza, inteligencja, kreatywność, zdolność do efektywnego podejmowania decyzji i rozwiązywania problemów), kompetencję językową (język ojczysty i język obcy oraz wszystkie aspekty związane z generowaniem tekstów i komunikacją interkulturową), kompetencję IT (obejmującą narzędzia i nowoczesne technologie potrzebne w pracy tłumacza) oraz kompetencję transferu (znaczenia pomiędzy dwiema rzeczywistościami językowymi). Interakcja pomiędzy tymi rodzajami kompetencji i jej wynik są czynnikami odróżniającymi przekład od innych domen, w których realizowana jest komunikacja. 
Ponieważ głównym przedmiotem artykułu jest dydaktyka przekładu z perspektywy kształtowania i rozwoju kompetencji tłumaczeniowej, warto $\mathrm{w}$ tym miejscu przenieść punkt ciężkości naszych rozważań. Interesujące dla nas podejście prezentuje Kelly (2005), która po analizie różnych definicji kompetencji tłumaczeniowej proponuje własną, koncentrującą się właśnie na dydaktyce. Otóż według niej kompetencja tłumaczeniowa to swoista makrokompetencja, na którą składają się różne umiejętności, zdolności, wiedza, a nawet sposób podejścia do wykonywanego zadania, a zatem cechy związane z przekładem jako czynnością wykonywaną przez ekspertów. Makrokompetencję Kelly rozbija na następujące składniki:

a) kompetencja komunikacyjna i tekstowa,

b) kulturowa,

c) tematyczna,

d) instrumentalna,

e) psychofizjologiczna,

f) interpersonalna,

g) strategiczna.

Powyższe składniki są ze sobą ściśle związane, a ich odpowiedni rozwój pozwala na stopniowe kształtowanie i nabywanie kompetencji tłumaczeniowej. Z perspektywy dydaktycznej istotna jest kompetencja komunikacyjna i tekstowa, ponieważ oznacza ona umiejętność rozumienia i analizowania różnych typów tekstów (zarówno pisemnych, jak i ustnych) z różnych dziedzin, umiejętność tworzenia różnych typów tekstów z różnych dziedzin oraz znajomość typowych cech i konwencji właściwych dla gatunków tekstów występujących w przekładzie ustnym i pisemnym. Proces kształtowania kompetencji tłumaczeniowej oparty jest $\mathrm{z}$ zasady na założeniu, że stanowi ona cel procesu dydaktycznego rozumianego jako wykształcenie w studencie umiejętności tworzenia odpowiedniego tekstu na podstawie poszerzających się zasobów wiedzy (ogólnej i specjalistycznej) oraz doświadczenia.

\section{Dydaktyka przekładu a przekład tekstów specjalistycznych}

Jak już wspomniano powyżej, w artykule odnosimy się do dydaktyki przekładu w ramach nauki języka, a nie do kształcenia tłumaczy, musimy zatem wziąć pod uwagę niejako oczywisty fakt, że nie wszyscy nasi studenci będą w przyszłości pracować zawodowo jako tłumacze (a mając zajęcia ze wszystkimi studentami na danym roku w ramach przedmiotu, musimy również mieć na względzie ich oczekiwania). Niemniej możemy starać się wykształcić w nich 
rodzaj kompetencji tłumaczeniowej potrzebnej filologowi w rzeczywistości świata globalnego. Na potrzeby niniejszego artykułu możemy ją nazwać „nieprofesjonalną kompetencją tłumaczeniową", w odróżnieniu od profesjonalnej kompetencji tłumaczeniowej, którą charakteryzują się doświadczeni, zawodowi tłumacze, a do osiągnięcia której aspirują studenci specjalistycznych studiów przekładowych. Określenie „nieprofesjonalna” odnosi się do osoby tłumacza (niezajmującego się więc zawodowo przekładem), lecz nie stoi do końca w sprzeczności z faktem, że kompetentnie przetłumaczony tekst nie musi być wyłącznie domeną absolwentów studiów przekładowych czy zawodowych tłumaczy.

Musimy również zwrócić uwagę na fakt, że kształcenie tłumaczy i dydaktyzacja przekładu w ramach komponentu praktycznej nauki języka (PNJ) to dwa odrębne pojęcia i cele kształcenia. W kształceniu tłumaczy studenci analizują proces i produkt przekładu, a także poszerzają wiedzę dotyczącą aspektów teoretycznych przekładu, natomiast w zajęciach z przekładu prowadzonych w ramach PNJ studenci są zainteresowani bardziej poszerzaniem słownictwa i konkretnych technik przekładu niż innymi kwestiami związanymi z tłumaczeniem. Należy jednak odejść od klasycznego (i anachronicznego) podejścia do takich zajęć, w którym priorytetem jest zachowanie adekwatności semantycznej tłumaczonych tekstów. Warto raczej skupić się na osiągnięciu funkcjonalnego efektu tłumaczenia (np. Kussmaul 1995), realizacji przyjętych celów komunikacyjnych (wypowiedzi lub tekstu), kontekstu, efektu stylistycznego w postaci zachowanych konwencji i reguł tekstowych, umiejętności poszukiwania i weryfikowania informacji jako podstawowej umiejętności tłumacza (np. Mackenzie 1998) oprócz umiejętności uzupełniania wiedzy dzięki korzystaniu ze źródeł i współpracy z innymi uczestnikami działań tłumaczeniowych.

Program nauczania przekładu w ramach PNJ - z racji kształcenia studentów, którzy po zakończeniu edukacji trafiają na rynek pracy - powinien w pewien sposób odpowiadać na potrzeby rynkowe, jak również określić cele kształcenia. Z drugiej jednak strony można zadać sobie pytanie, czy na zajęciach powinniśmy naśladować prawdziwe sytuacje, które mogą się wydarzyć w życiu zawodowym. Można zgodzić się z Bernardini (2004), że celem zajęć jest również pogłębiona edukacja studentów polegająca na uświadomieniu złożoności procesu tłumaczeniowego, umiejętności refleksji nad własną pracą, czego skutkiem ma być wykształcenie indywidualnych strategii tłumaczeniowych, kreatywnego radzenia sobie z niespodziewanymi problemami (co częściowo pokrywa się z proponowaną przez Kiraly’ego [2000] kompetencją tłumacza, czyli translator competence). Z kolei González Davies (2004) pro- 
ponuje przekształcenie zajęć $\mathrm{z}$ tłumaczenia $\mathrm{w}$ szerokie forum wymiany myśli, praktycznych wskazówek, zaleca dostosowanie technik i metod do stylów uczenia się studentów, jasne określenie celów kursu, ewolucyjne - zgodne ze stopniem trudności danych tekstów - omawianie materiału, tworzenie projektów pozwalających na kontakt z profesjonalnymi tłumaczami poza kontekstem edukacyjnym oraz umożliwienie studentom uczestnictwa w prawdziwych zadaniach tłumaczeniowych.

Można więc pokusić się o sporządzenie listy celów, które chcielibyśmy osiągnąć w trakcie procesu dydaktyzacji przekładu. Obejmuje ona takie komponenty jak np. uświadomienie studentom etapów i znaczenia procesu tłumaczeniowego, rozwijanie odpowiednich strategii tłumaczeniowych, wprowadzenie teorii przekładu jako wiedzy niezbędnej do prawidłowego dokonywania operacji tłumaczeniowych, poszerzania znajomości języka ojczystego i obcego, stosowania w odpowiedni sposób specjalistycznej terminologii, wiedzy oraz narzędzi wyszukiwania informacji. Innymi słowy naszym celem jest nie tylko kształcenie tłumacza rozumiane jako doskonalenie umiejętności językowych i pozajęzykowych, ale przede wszystkim wieloaspektowa edukacja tłumacza, kształtowanie w nim postaw pozwalających na umotywowane poszerzanie wiedzy, chęć dalszej nauki, świadomość odpowiedzialności za tworzony tekst i znaczenie komunikacji interkulturowej. W ten sposób możemy mówić o kształtowaniu nie tylko kompetencji tłumaczeniowej, ale kompetencji jednostki, tłumacza, która jest zdolna do refleksji nad własnym warsztatem i tworzonymi przez siebie tekstami, a tym samym jest w stanie krytycznie odnieść się do swoich umiejętności, dostrzec problemy i pojawiające się deficyty w konkretnej domenie oraz rozwinąć zdolności poznawcze. Zwolennikiem takiego właśnie podejścia, skoncentrowanego na potrzebach jednostki, był Kiraly $(1995,2000)$, który postulował wprowadzenie autentycznych tekstów i zadań tłumaczeniowych do procesu dydaktycznego, co ma prowadzić do większej autonomii studenta, rozwijania umiejętności tłumaczeniowych i interpersonalnych, wiedzy i kompetencji. Oczywista jest w tej sytuacji konieczność redefinicji roli nauczyciela, który ma służyć pomocą $\mathrm{w}$ procesie, a student może w ten sposób budować własną niezależność i zwiększać zakres swojej kompetencji tłumaczeniowej. Nauczyciel zatem przestaje być niejako wyrocznią dającą jedyne i prawdziwe odpowiedzi i podsuwającą rozwiązania problemów, ale jego zadaniem jest raczej stworzenie fundamentów, na których opiera się proces dydaktyczny, a z których może skorzystać student, zwiększając zakres odpowiedzialności za powstający tekst (por. Kościałkowska-Okońska 2007). Rola studenta w tak postrzeganym procesie dydaktycznym jest znacznie większa: student aktywnie uczestniczy 
w procesie, angażuje się w tworzenie programu nauczania, dobór materiałów do analizy, ocenę własnej pracy, ale również ocenę programu.

W sytuacji, z którą mamy obecnie do czynienia w rzeczywistości uniwersyteckiej, można stwierdzić, że kształcenie filologiczne w dużej mierze nie stanowi odpowiedzi na wyzwania i potrzeby współczesnego rynku z racji dostosowania programów nauczania do założeń i celów edukacyjnych danej instytucji czy jednostki. Postulować można by zatem na przykład umożliwienie studentom kontaktów z profesjonalnymi tłumaczami czy agencjami tłumaczeniowymi w ramach programu studiów, ocenę studentów opartą nie na testach czy zaliczeniach, ale portfolio z przetłumaczonymi tekstami z danej dziedziny i przygotowanymi glosariuszami, stosowanie prawdziwych tekstów do tłumaczenia, kształtowanie umiejętności i kompetencji w sposób przystający do potrzeb rynku usług tłumaczeniowych. Studenci muszą nauczyć się, w jaki sposób efektywnie współpracować nie tylko z innymi tłumaczami, ale także z terminologami, osobami zarządzającymi danym projektem czy też z klientami. Nie są też wyłącznie pasywnymi odbiorcami informacji, lecz muszą również umieć wyszukiwać potrzebne im informacje i dokonywać krytycznej oceny ich przydatności. Ocena ich pracy w postaci uwag czy komentarzy (w bardziej lub mniej sformalizowany sposób) dotyczących wykonanych przez nich tłumaczeń również nie może być tylko bierna - studenci sami muszą nauczyć się (przy wsparciu nauczyciela) obowiązujących standardów w pracy tłumacza jak również zasad etycznych obowiązujących tłumaczy, czy to w postaci istniejącego i obowiązującego kodeksu praktyk zawodowych, czy norm wewnętrznych w danej agencji tłumaczeniowej, czy też w końcu własnych indywidualnych norm. Jest to możliwe głównie za sprawą pracy $\mathrm{z}$ autentycznymi tekstami (lub - jeśli istnieje taka szansa - dzięki praktykom zawodowym). Taka perspektywa edukowania tłumacza wymaga od instytucji (uczelni) zgody na większą autonomię, ale tym samym odpowiedzialności studenta, w przeciwieństwie do jego biernej roli jako „nośnika” umiejętności wyłącznie natury technicznej (w tym wypadku stricte językowej). Większa odpowiedzialność i autonomia studenta to większy - i aktywny - jego udział w działaniach różnych kręgów zawodowych związanych z tłumaczeniem. Takie podejście można jednak realizować wyłącznie w programach tłumaczeniowych trwających dłużej niż jeden lub dwa semestry (czyli programach specjalizacyjnych lub studiach podyplomowych kształcących tłumaczy, przy znacznie większej liczbie godzin zajęć), wymaga ono bowiem długotrwałego wysiłku obu stron uczestniczących w procesie dydaktycznym: nauczyciela i studenta, wymaga motywacji, zaangażowania i również - co należy podkreślić - zmiany w percepcji miejsca przekładu na kierunkach filologicznych. 
Nasuwa się jednocześnie pytanie, czy wszystkie strony tej istotnej układanki są gotowe do tak znaczącej i daleko idącej zmiany...

Obecnie obserwujemy ciągle zwiększający się popyt na usługi tłumaczeniowe, zwłaszcza gdy spojrzymy na ten fakt z perspektywy Unii Europejskiej i wymaganej prawem konieczności tłumaczenia wszystkich tekstów unijnych na język polski. Większy popyt wymaga zaspokojenia, stąd też wynika popularność zarówno programów tłumaczeniowych prezentowanych w ramach oferty dydaktycznej na poziomie uniwersyteckim, jak i kandydatów chętnych do zgłębiania tajników zawodu, poszerzania wiedzy i rozwijania kompetencji tłumaczeniowej, które to cechy stanowią o konkurencyjności studenta na rynku pracy. Można jednak zastanowić się, czy za tymi szybkimi i dynamicznymi zmianami na rynku jest w stanie nadążyć dydaktyka przekładu, która $\mathrm{z}$ wielu różnych powodów pozostaje jednak w dużej mierze odizolowana od praktyki tłumaczeniowej w rozumieniu warunków rynkowych, w których funkcjonują tłumacze. Nie takie zresztą do końca jest zadanie dydaktyki przekładu na kierunkach filologicznych; jej zadaniem jest przygotowanie kandydata/studenta do sprostania wymaganiom w przyszłości czy oferowania mu narzędzi (nie tylko natury technicznej) i wyposażenia go w różnorakie kompetencje potrzebne do funkcjonowania na rynku pracy, ale również w aparat pojęciowy umożliwiający podejmowanie zadań badawczych.

Należy ponadto rozróżnić potrzeby studenta kierunku filologicznego, gdzie w programie znajduje się tłumaczenie, od studenta specjalistycznych studiów przekładowych - ich doświadczenia, potrzeby i oczekiwania, ale również kompetencje i umiejętności będą się różnić. Nie należy tutaj wprowadzać hierarchizacji priorytetów w dydaktyce czy gradacji stopni kompetencji dla poszczególnych typów studiów i studentów. Zarówno wykładowcy na studiach kierunkowych, specjalistycznych, jak i prowadzący przedmioty związane z tłumaczeniem na kierunkach filologicznych powinni postawić sobie jeden cel: kształcenie kompetentnych specjalistów językowych, zdolnych do sprostania wyzwaniom w pracy zawodowej, która może wymagać umiejętności tłumaczenia. A zatem dydaktyka przekładu to nie tylko nauczanie, ale również edukacja jednostki na wielu płaszczyznach. Kształcenie ma na celu proces gromadzenia wiedzy, natomiast wieloaspektowa edukacja stawia sobie za priorytet rozwój (również intelektualny) jednostki oraz jej zwiększającą się samodzielność i autonomię przy rozwoju umiejętności rozwiązywania problemów. Zarówno kształcenie, jak i edukacja mogą być wykorzystane $\mathrm{w}$ procesie dydaktycznym według indywidualnych potrzeb i oczekiwań studentów, w zależności od ich życiowych celów, umiejętności, talentu, zdolności, wiary we własne możliwości oraz podejmowanych życiowych wyborów 
dotyczących przyszłej kariery zawodowej. Student poddany nie tylko procesowi kształcenia, ale również edukacji na wielu płaszczyznach oprócz wiedzy ma jeszcze ogólne predyspozycje, aby sprostać wyzwaniom w zadaniach tłumaczeniowych, umie je w sposób kreatywny, lecz również krytyczny zastosować w tworzeniu przekładu, ma umiejętności przydatne w pracy zawodowej (techniki komputerowe, znajomość narzędzi wspomagających tłumaczenie etc.). W trakcie procesu dydaktycznego i ekspozycji na wieloaspektową edukację wiedza i kompetencja studenta dotyczące tłumaczenia w sposób oczywisty się zwiększają, co wynika z procesu kształcenia i nabywania umiejętności w ramach praktyki tłumaczeniowej.

Jednym z przykładów takiej praktyki mogą być zajęcia z przekładu specjalistycznego (w tym konkretnym przypadku przekładu tekstów prawnych i prawniczych, realizowanych przez autorkę artykułu w ramach modułu język prawa na trzecim roku studiów licencjackich). Celem zajęć było wykształcenie w studentach przede wszystkim dobrych praktyk tłumaczeniowych, efektywnych strategii tłumaczenia, umiejętności wyszukiwania potrzebnych informacji z wykorzystaniem dostępnych źródeł, poszerzenie wiedzy dotyczącej aspektów prawnych funkcjonowania w nowoczesnym świecie i gospodarce. Zajęcia trwały przez 2 semestry, w wymiarze 2 godzin tygodniowo. $\mathrm{W}$ trakcie realizacji programu skupiono się na analizie tekstu, omówiono cechy językowe (w tym semantyczne) tekstów prawnych oraz potrzebną terminologię. Zwrócono uwagę na konieczność utrzymania konsekwencji w stosowaniu terminów w przekładzie. Do ćwiczeń praktycznych wykorzystano materiały autentyczne, w tym akty małżeństwa i urodzenia, dokumenty unijne (np. deklaracje zgodności), umowy czy akty notarialne. Studenci byli oceniani na podstawie okresowych testów sprawdzających zakres omawianego w danym okresie materiału (a także zadań tłumaczeniowych do samodzielnej realizacji w ramach monitorowanego regularnie portfolio). Testy polegały na przetłumaczeniu (na język polski i angielski) tekstów z określonych działów tematycznych. Studenci nie tylko otrzymywali gotowe glosariusze oraz wskazówki, w jakich źródłach można znaleźć przydatne informacje, ale również sami tworzyli własne glosariusze, z których korzystali w trakcie wykonywania zadań tłumaczeniowych.

Po zakończeniu kursu studenci wypełnili ankietę (ogółem 45 osób) z pytaniami odnoszącymi się do kwalifikacji i umiejętności, które można uzyskać, najczęściej pojawiających się problemów czy czasu trwania kursu. $Z$ uzyskanych odpowiedzi wynika wyraźnie, że przedmiot ten stanowi wyzwanie dla studentów z racji nieznajomości (lub bardzo małej znajomości) zagadnień prawnych (40 wskazań), niskiej świadomości ich znaczenia dla życia w no- 
woczesnym państwie czy poczucia braku znajomości gramatyki języka obcego na poziomie umożliwiającym tłumaczenie tak złożonych (i odmiennych) gramatycznie i semantycznie tekstów (38 wskazań). Studenci wskazali ponadto na konieczność ujęcia $\mathrm{w}$ programie studiów zajęć $\mathrm{z}$ wprowadzenia aspektów prawa polskiego i angielskiego (32 wskazania), aby możliwe było pogłębienie wiedzy dotyczącej tych kwestii, postulowali również zwiększenie tygodniowego wymiaru godzin przedmiotu ze względu na jego przydatność w przyszłym życiu zawodowym (37 wskazań). Co więcej, studenci, którzy nie upatrują w przekładzie sposobu na kontynuowanie ścieżki zawodowej, są jednak zdania, że jest to przedmiot przydatny ze względów czysto „technicznych", a mianowicie służy pogłębieniu znajomości języka obcego i jego struktur, uświadamia konieczność doskonalenia kompetencji językowej i pozajęzykowej nie tylko w języku obcym (40 wskazań), ale także w języku ojczystym (23 wskazania), wymaga pewnej dyscypliny i systematyczności w przyswajaniu materiału (19 wskazań). Innymi słowy, mimo stopnia skomplikowania i jednak pewnej obcości aparatu pojęciowego przedmiot stanowi element nie tylko kształcenia tłumaczeniowego, ale również edukacji odnoszącej się do kwestii pozajęzykowych, do pogłębienia wiedzy dotyczącej zagadnień prawnych, do znajomości etapów procesu tłumaczeniowego, znaczenia wiedzy dla tworzonych przez tłumacza tekstów czy też w końcu świadomości znaczenia wykonywanej pracy.

\section{Uwagi końcowe}

W kształtowaniu kompetencji tłumaczeniowej język jest tylko jednym $\mathrm{z}$ instrumentów niezbędnych do efektywnego wykorzystania strategii i technik, które przyczyniają się do tworzenia dobrej jakości przekładu. Czynnikiem, który ma duże znaczenie dla możliwości rozwoju kompetencji tłumaczeniowej, jest niezbędna wewnętrzna motywacja i chęć uczenia się, pogłębiania zdobytej wiedzy i poszukiwania potrzebnych informacji. Niestety, należy przyznać, że nie zawsze taka postawa jest powszechna wśród studentów. Może ona częściowo wynikać z przekonania o znajomości języka, nawet jeżeli ta znajomość jest bardziej powierzchownej natury, pojawiają się problemy gramatyczne w tworzeniu tekstów, a wiedza dotycząca aspektów pozajęzykowych nie jest tak obszerna, jak być powinna. Być może wynika to z przekonania, żywionego przez część studentów, że język to tylko instrument w osiąganiu celów, przydatny w realizacji zadań tłumaczeniowych, natomiast niewiążący się z koniecznością pogłębiania wiedzy dotyczącej rzeczywistości 
pozajęzykowej, bez której język tak naprawdę nie funkcjonuje.

Ponadto musimy również, jak już wspomniano powyżej, odróżnić nauczanie tłumaczenia od wieloaspektowej edukacji przyszłych tłumaczy i studentów kierunków filologicznych z komponentem tłumaczeniowym. Edukacja wieloaspektowa to holistyczne podejście do kształtowania potencjału intelektualnego i społecznego studenta. Nasz sukces dydaktyczny jest w dużej mierze uzależniony od faktu, że nauczanie przekładu na poziomie uniwersyteckim na kierunkach filologicznych to nie tylko abstrakcyjne i osobne pojęcia „nauczania” i „edukacji wieloaspektowej”. To połączenie obu tych czynników sprawi, że studenci nie tylko zdobędą umiejętność tłumaczenia tekstów i będą znali techniki oraz strategie konieczne do realizacji tego celu, ale również będą jednostkami kreatywnymi, których potencjał może być wykorzystany w nowoczesnym społeczeństwie. Przyjmując odpowiedzialność za kształcenie studentów, musimy również wziąć pod uwagę potrzeby rynku i oczekiwania potencjalnych pracodawców, aby nasi studenci mogli $\mathrm{z}$ jednej strony być dobrze wykształceni, mieć zaplecze intelektualne, umiejętności językowe, strategie i techniki oraz znajomość instrumentów potrzebnych do poszukiwania niezbędnych informacji, ale również żeby wyposażeni $\mathrm{w}$ te zdolności i techniki mogli być konkurencyjni na rynku pracy oraz byli zmotywowani do ustawicznego kształcenia i rozwijania swoich umiejętności oraz wiedzy. Oczywiste jest, że proces kształcenia, nabywania wiedzy i gromadzenia doświadczenia jest priorytetem pracy tłumacza. Naszym zadaniem i obowiązkiem jako dydaktyków przekładu jest ukazanie drogi, sposobu oraz narzędzi, za pomocą których nasi studenci będą mogli rozwijać i kształtować nie tylko kompetencję tłumaczeniową, ale przede wszystkim indywidualną kompetencję tłumacza.

\section{Literatura}

Albir, H.A., 2005,. „A aquisição da competência tradutória. Aspectos teóricos e metodológicos", [w:] Competência em tradução.Cognição e discurso, A. Pagano, C. Magalhães, F. Alves (red.), Belo Horizonte, s. 10-42.

Alves, F., (red.), 2003, Triangulating Translation: Perspectives in Process Oriented Research, Amsterdam.

Alves, F., Gonçalves, J.L., 2003, „A relevance theory approach to the investigation of inferential processes in translation", [w:] Triangulating translation: perspectives in process oriented research, F. Alves (red.), Amsterdam, s. $11-34$. 
Alves, F., 1995, Zwischen Schweigen und Sprechen: Wie bildet sich eine transkulturelle Brücke?: eine psycholinguistisch orientierte Untersuchung von Übersetzungsvorgängen zwischen portugiessischen und brasilianischen Übersetzern, Hamburg.

Anderson, J.R., 1983, The architecture of cognition, Cambridge.

Beeby, A., Ensinger, D.,Presas, M., (red.), 2000, Investigating Translation Competence, Amsterdam.

Bernardini, S., 2004, „The theory behind the practice: Translator training or translator education?", [w:] Translation in Undergraduate Degree Programmes, K. Malmkjaer (red.), Amsterdam-Philadelphia, s. 17-29.

Chesterman, A., 1997, Memes of translation, Amsterdam.

Danks, J.H. i in., 1997, Cognitive processes in translation and interpreting, California.

Dreyfus, H.L., Dreyfus, S.E., 1986, Mind over Machine. The Power of Human Intuition and Expertise in the Era of the Computer, Oxford.

Englund Dimitrova, B., Expertise and Explicitation in the Translation Process, Amsterdam-Philadelphia.

Ericsson, K.A., Smith, J., 1991, „Prospects and Limits of the Empirical Study of Expertise: An Introduction", [w:] Towards a General Theory of Expertise.Prospects and Limits, K.A. Ericsson, J. Smith (red.), Cambridge, s. $1-38$.

Gambier, Y., 2005, Translation and Interpretation - Training and Research, Turku..

Gerloff, P., 1986, „Second Language Learners' Reports on the Interpretive Process", [w:] Interlingual and Intercultural Communications. Discourse and Cognition in Translation and Second Language Acquisition Studies, J. House, S. Blum-Kulka (red.), Tübingen, s. 243-262.

Gonzalez Davies, M., 2004, Multiple Voices in the Translation Classroom. Activities, Tasks and Projects, Amsterdam-Philadelphia.

Hałas, B., 1995, Terminologia języka prawnego, Zielona Góra.

Hönig, H.G., 1995, Konstruktives Übersetzen. (Studien zur Translation 1), Tübingen.

Jääskeläinen, R., 1989, „The Role of Reference Material in Professional vs. Non-professional Translation", [w:] Empirical Studies in Translation and Linguistics. (Studies in Languages 17)], S. Tirkkonen-Condit, S. Condit, S. Joensuu (red.), s. 175-198.

Jääskeläinen, R., 1993, „Investigating Translation Strategies”, [w:] Recent Trends in Empirical Translation Research, S. Tirkkonen-Condit, J.Laffling, Joensuu (red.), s. 99-120. 
Jäskeläinen, R., 1996, „Hard work will bear beautiful fruit. A Comparison of Two Think-Aloud Protocols", Meta, 46(1), s. 60-74.

Jäskeläinen, R., 1999, Tapping the Process. An Explorative Study of the Cognitive and Affective Factors Involved in Translating. (Publications in the Humanities 22), Joensuu.

Jääskeläinen, R., 2002, „Think-aloud Protocol Studies into Translation. An Annotated Bibliography", [w:] Target, Vol. 14, No. 1, s. 107-136.

Jääskeläinen, R., Tirkkonen-Condit, S., 1991, „Automatised Processes in Professional vs. Nonprofessional Translation: A Think-aloud Protocol Study", [w:] Empirical Research in Translation and Intercultural Studies: Selected Papers of the TRANSIF Seminar, S. Tirkkonen-Condit (red.), Tübingen, s. 89-109.

Jadacka, H., 1996, „Styl tekstów prawnych na tle innych odmian polszczyzny”, [w:] Przegląd Legislacyjny Nr 3.s. 112-128.

Jopek-Bosiacka, A., 2006, Przekład prawny i sadowy, Warszawa.

Kelly, D., 2005, A Handbook for Translator Trainers, Manchester.

Kiraly, D.C., 1995, Pathways to Translation: Pedagogy and Process, Kent.

Kiraly, D., 2000, A Social Constructivist Approach to Translator Education. Empowerment from Theory to Practice, Manchester.

Kościałkowska-Okońska, E., 2007, „Analiza wyzwań i zagrożeń dla dydaktyki przekładu na kierunkach filologicznych. Przedefiniowanie roli nauczyciela i studenta", [w:] Wspótczesne kierunki analiz przekładowych, M. Piotrowska (red.), Kraków, s. 261-267.

Kościałkowska-Okońska, E., 2012, „Kompetencja tłumaczeniowa: modele teoretyczne a rzeczywistość, [w:] Tłumacz: sługa, pośrednik, twórca?, M. Guławska-Gawkowska, K. Hejwowski, A. Szczęsny (red.), Warszawa, s. $119-129$.

Krings, H.P., 1986, Was in den Köpfen von Übersetzern vorgeht, Tübingen.

Krings, H.P., 1988, „Blick in die »Black Box « - Eine Fallstudie zum Übersetzungsprozeß bei Berufsübersetzern", [w:] Textlinguistik und Fachsprache. Akten des Internationalen übersetzungswissenschaftlichen AILA-Symposions, R. Arntz, R. Olms (red.), Hildesheim, s. 393-412.

Kußmaul, P., 1995, Training the Translator, Amsterdam.

Lörscher, W., 1991, Translation Performance, Translation Process, and Translation Strategies. A Psycholinguistic Investigation, Tübingen.

Malmkjær, K., (red.), 1998, Translation and Language Teaching. Language Teaching and Translation, Manchester.

Malmkjaer, K., (red.), 2004, Translation in Undergraduate Degree Programmes, Amsterdam-Philadelphia. 
PACTE 2000, „Acquiring Translation Competence: Hypotheses and Methodological Problems in a Research Project", [w:] Investigating Translation Competence, A. Beeby, D. Ensinger, M. Presas (red.), Amsterdam, s. 99-106.

Sarcevic, S., 1997, New Approach to Legal Translation, the Hague.

Schäffner, C., Adab, B., (red.), 2000, Developing translation competence, Amsterdam.

Séguinot, C., 1989, The translation process, Toronto.

Sternberg, R.J., 1999, Cognitive Psychology, Fort Worth.

Tiersma, P.M., 1999, Legal Language, Chicago.

Tirkkonen-Condit, S., 1990, „Professional vs. non-professional translation: a think-aloud protocol study", [w:] Learning, Keeping and Using Language, M.A.K. Halliday, J. Gibbons, H. Nicholas (red.), Amsterdam, s. 381-394.

Tirkkonen-Condit, S., 1992, „The Interaction of World Knowledge and Linguistic Knowledge in the Processes of Translation", [w:] Translation and Meaning, 2, B. Lewandowska-Tomaszczyk, M. Thelen (red.), Maastricht, s. $433-440$.

Tirkkonen-Condit, S., 1992, „The interaction of world knowledge and linguistic knowledge in the process of translation: a think-aloud protocol protocol study", [w:] Translation and Meaning, 2B, Lewandowska-Tomaszczyk, M. Thelen (red.), s. 433-440. Maastricht: Euroterm.

Toury, G., 1995, Descriptive Translation Studies and Beyond, Amsterdam.

Wojtak, M., 2001, „Styl urzędowy”, [w:] Współczesny język polski, J. Bartmiński (red.), Lublin, s. 141-149.

\section{Teaching translation of specialist texts in view of translation competence development}

Summary

Translators nowadays are to face challenges, meeting which entails constant broadening of knowledge, familiarizing themselves with new technologies and translation techniques, or acquiring new skills of searching for information. This article addresses the field of translating specialist texts (legal texts in particular) from the point of view of translation teaching. Since the growing demand for translation - and good quality translation, produced by competent translators, in particular in the globalized world can be observed on a regular basis, the necessity has also emerged to have a closer look at the way translation competence is and can potentially be developed. Existing approaches to competence cover a variety of aspects from the 
wide spectrum of linguistics, psycholinguistics or cognitive studies; this variety of competence components may result in postulating component models. The awareness of the role of competence and the significance of the didactic process are discussed above, with the focus being placed on the dynamically changing perception of the role of main actors in the teaching/learning process. Having in mind the development of competence seen from the didactic perspective, the following factors should be considered:

1. the need to raise the awareness of students as to potential problem areas (i.e. to underline the significance of such extralinguistic concepts as e.g., background knowledge or cognitive factors),

2. the need to make students aware of their responsibility for tasks performed as active, not passive, participants of translation interactions,

3. changing market requirements and expectations as to skills and qualifications students should have to be highly appreciated and competitive employees. 